Rheumatology Unit, University of Bristol Division of Medicine, Bristol Royal

Infirmary, Bristol

C Salisbury

M Sharif

Correspondence to: Dr M Sharif, Rheumatology Unit, University of Bristol Division of Medicine, Bristo Royal Infirmary, Marlborough Street, Bristol BS2 8 HW.

\title{
Relations between synovial fluid and serum concentrations of osteocalcin and other markers of joint tissue turnover in the knee joint compared with peripheral blood
}

\author{
C Salisbury, M Sharif
}

\begin{abstract}
Objective-To determine if osteocalcin $(O C)$ is locally produced in the joint and to study the relation between markers of bone, cartilage, and synovial tissue turnover.

Methods-The concentrations of OC, keratan sulphate epitope (5D4), and hyaluronate (HA) were measured in paired serum and synovial fluid in 10 healthy volunteers and 15 patients with osteoarthritis (OA) and 16 with rheumatoid arthritis (RA). OC was measured with a commercial immunoradiometric assay and concentrations of 5D4 and HA were measured using enzyme linked immunosorbent inhibition assays.

Results-Synovial fluid OC was found to be significantly lower than serum $(p<$ 0.001 ) in all patients and controls. Synovial fluid OC concentrations were directly correlated with serum concentrations $(r=0.63, p<0.001)$ and with age $(r=$ $0.48, \mathrm{p}<0.01)$. There were also some relations between OC, HA, and $5 \mathrm{D} 4$ in patients with $O A$ and $R A$. The OC concentrations were directly correlated with HA $(r=0.68, p<0.01)$ in $O A$ serum and there was a similar correlation in RA synovial fluid $(r=0.69, p<0.01)$. A weak negative correlation was found between OC and 5D4 in OA serum $(r=-0.55$, $\mathbf{p}=0.035)$ while a weak positive correlation was found in $\mathrm{RA}$ serum $(r=0.53, p=0.034)$. Conclusions-These results show that more OC is present in the circulation than in knee joint fluids suggesting that synovial fluid OC may be derived from the blood.
\end{abstract}

(Ann Rheum Dis 1997;56:558-561)

Currently available clinical and radiographic methods used to assess osteoarthritis (OA) and rheumatoid arthritis (RA), such as anatomical changes in an affected joint, can only provide crude, insensitive measures of disease activity and outcome. Biochemical marker is a promising new tool for the investigation of joint disease. Measurement of markers in synovial fluid probably provide the most accurate reflection of the current metabolic status of arthritis in any one joint, ${ }^{1}$ whereas serum concentrations provide information on the systemic turnover of metabolites in a person.

Osteocalcin (OC), a proposed marker of bone formation, ${ }^{1-3}$ has been studied widely in serum and synovial fluid from patients with joint disease, ${ }^{3-5}$ however it remains unclear whether OC is produced locally in the joint or derived from the blood. Therefore, the main objective of this study was to determine the source of OC production in both arthritis and normal condition. In addition, serum and synovial fluid concentrations of OC were correlated with values of putative markers of cartilage damage and synovial inflammation to test the hypothesis that measurement of different matrix component markers in body fluids may provide an insight into the relation between different tissues within the joint organ.

\section{Methods}

PATIENTS

Local ethical committee approval was obtained for the study. The study included 15 patients with OA whose diagnosis was based on the combination of use related pain and radiographic changes of definite OA (Kellgren and Lawrence grade 2 or above) ${ }^{6}$ and 16 with diagnosis of RA (Larsen index 3-5) using the American College of Rheumatology criteria. ${ }^{7}$ Ten healthy people with no knee pain and no history or signs of joint disease (controls) were used in the study. The control subjects were not matched for age or sex with either the OA or RA groups. Both the patients and the control group have been described in more detail previously. ${ }^{8}$

\section{STUDY DESIGN}

Synovial fluid and serum were collected, processed, and stored at $-70^{\circ} \mathrm{C}$ until analysis as reported previously. ${ }^{8}$ Serum and synovial fluid OC were measured using a solid phase 'sandwich' immunoradiometric assay (ELSAOSTEO (CIS bio international, ORIS Group, Gif-sur-Yvette, France)), which uses a monoclonal antihuman OC antibody specific 

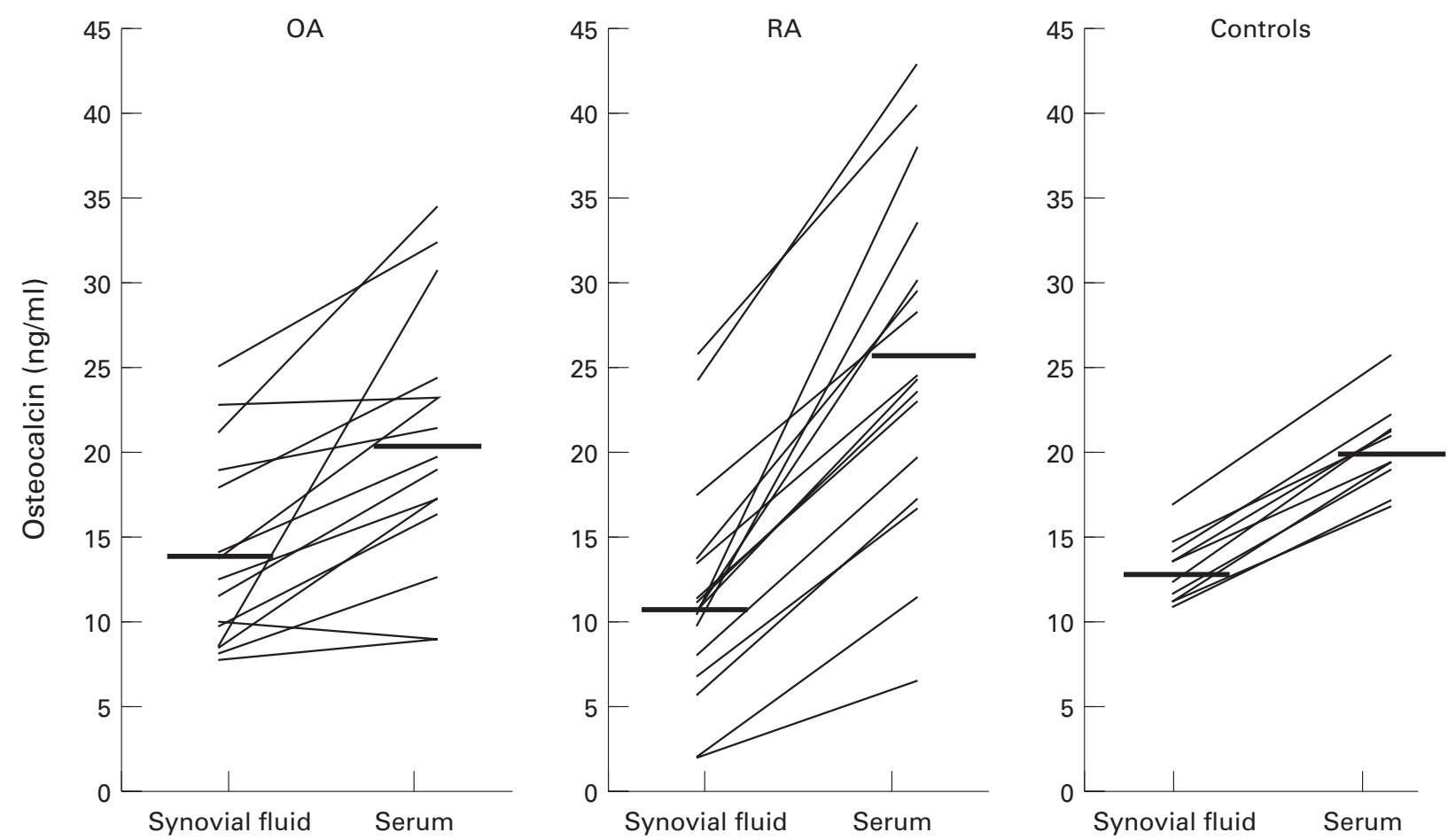

Figure 1 Concentrations of osteocalcin (OC) in paired synovial fluid and serum from patients with $O A$ and $R A$ and healthy controls. Horizontal bars show the mean value in each group.

for the whole molecule (carboxylated or decarboxylated) and OC peptide 1-43 (the antibody does not recognise human OC peptides 7-19, 25-37 and 37-49; CIS bio international). The assay has a detection limit of $0.4 \mathrm{ng} / \mathrm{ml}$ with intra-assay and inter-assay variations of less than $1 \%$. Measurement was on previously undefrosted paired serum and synovial fluid and all samples were assayed in duplicate.

Serum and synovial fluid keratan sulphate epitope (5D4) and hyaluronate (HA) were measured using ELISAs ${ }^{910}$ with some minor modifications. ${ }^{11}$

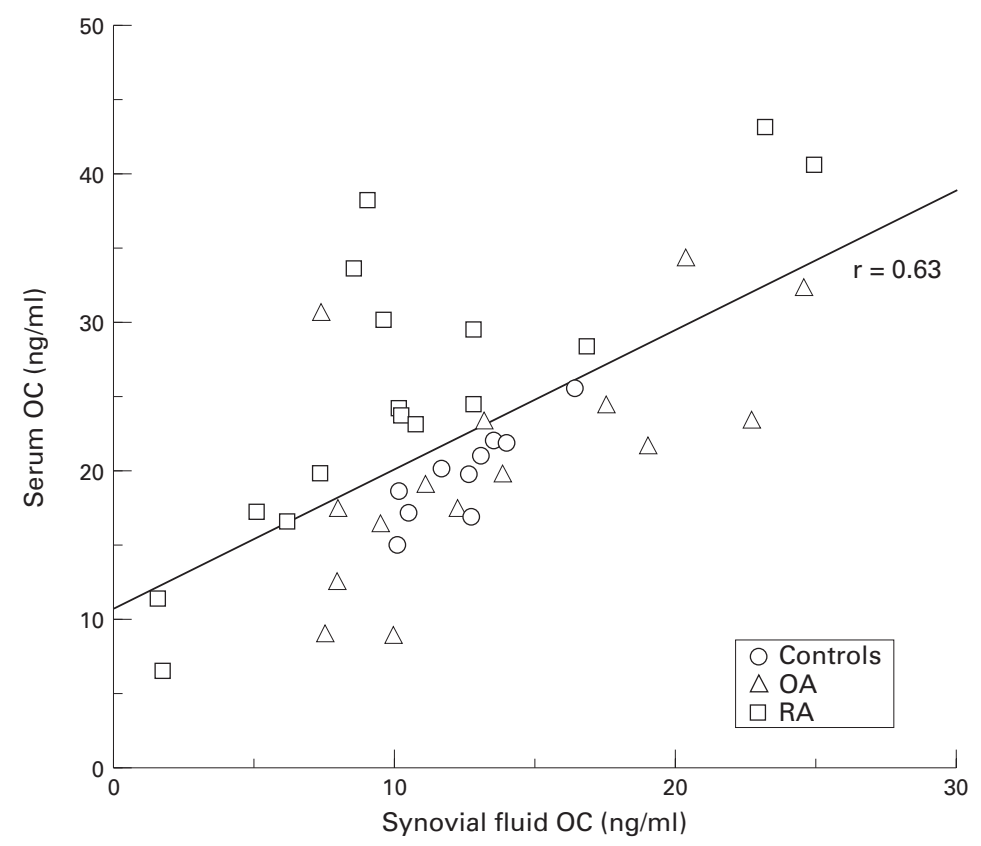

Figure 2 Correlation between serum and synovial fluid OC concentrations.
STATISTICAL ANALYSIS

The HA and KS values were logarithmically transformed (natural log; Ln) before analysis. Correlations were calculated using Pearson product-moment coefficient and for nonparametric data (untransformed) Spearman's correlation coefficient was used. Student's two tailed unpaired $t$ tests were used to compare between group differences. Statistical significance was set at the $5 \%$ level.

\section{Results}

There was no significant difference between the OA and RA patients with respect to age (mean 66.5, range 53-81; and 60.3, 29-78 years respectively) or sex (male:female 6:9 and 4:12 respectively). The normal controls however were significantly younger (mean 49.9 , range $40-52$ years; $p<0.01$ ) than the OA and RA patients and had higher male:female ratio $(7: 3)$.

Synovial fluid and serum OC increased linearly with age $(r=0.48, \mathrm{p}=<0.01$ in both cases) and synovial fluid OC was significantly lower than serum $(\mathrm{p}<0.001)$ in all patients and controls. Moreover, synovial fluid OC concentrations (mean (SD)) were higher in men compared with women (14.03 (4.71) $v$ 11.06 (5.81); $p=0.082$ ). Figure 1 shows the relation between paired serum and synovial fluid OC concentrations in each patient and controls. To allow for known variations in serum OC with age and other possible between patient differences in serum OC concentrations, the synovial fluid/serum OC ratios was calculated for each subject and then compared between groups. The ratio of synovial fluid/serum OC was similar in OA and controls (mean (SD), $0.69(0.21) v 0.63(0.06)$ ). How- 
Table 1 Serum and synovial fluid concentrations of osteocalcin (OC), keratan sulphate epitope 5D4, and hyaluronate (HA) in patients with osteoarthritis, rheumatoid arthritis, and healthy controls

\begin{tabular}{|c|c|c|c|c|c|c|}
\hline \multirow[b]{2}{*}{ Marker } & \multirow[b]{2}{*}{$O A$} & \multirow[b]{2}{*}{$R A$} & \multirow[b]{2}{*}{ Controls } & \multicolumn{3}{|l|}{$p$ Values } \\
\hline & & & & $\begin{array}{l}O A v \\
R A\end{array}$ & $\begin{array}{l}O A v \\
\text { controls }\end{array}$ & $\begin{array}{l}R A v \\
\text { controls }\end{array}$ \\
\hline $\begin{array}{l}\text { SF OC } \\
(\mathrm{ng} / \mathrm{ml})\end{array}$ & $1371(5.83)$ & $10.67(6.58)$ & $12.47(1.97)$ & 0.183 & 0.457 & 0317 \\
\hline Serum OC & $20.68(7.76)$ & $25.68(10.17)$ & $19.80(3.31)$ & 0.091 & 0.698 & 0.054 \\
\hline Ln sf HA & $11.53(0.62)$ & $11.32(0.43)$ & $12.23(0.13)$ & 0.303 & $<0.001$ & $<0.001$ \\
\hline LN serum HA & $4.93(0.56)$ & $5.03(0.74)$ & $4.14(0.33)$ & 0.649 & $<0.001$ & $<0.001$ \\
\hline Ln SF 5D4 & $9.23(0.48)$ & $8.78(0.89)$ & $10.70(0.21)$ & 0.087 & $<0.001$ & $<0.001$ \\
\hline Ln serum 5D4 & $6.38(0.13)$ & $6.33(0.18)$ & $6.44(0.14)$ & 0.412 & 0.246 & 0.079 \\
\hline
\end{tabular}

Values expressed as mean $(\mathrm{SD}) . \mathrm{SF}=$ synovial fluid; $\mathrm{Ln}=$ natural $\log , \mathrm{p}$ values are from unpaired two tailed Student's $t$ test.

ever, the ratio was significantly lower in RA than OA and controls $(0.39(0.14) ; \mathrm{p}<0.001$ and $\mathrm{p}<0.01$ respectively). Figure 2 shows the overall correlation $(r=0.63)$ between serum and synovial fluid OC concentrations in all subjects. The correlation was stronger in the controls $(r=0.87, \mathrm{p}<0.001)$ and RA $(r=0.82$, $\mathrm{p}<0.001)$, than in the OA group $(r=0.65$, $\mathrm{p}<0.01)$.

Table 1 shows the concentrations of OC and other markers. There were no significant differences in serum OC and 5D4 between groups but serum HA was significantly higher in the $\mathrm{OA}$ and RA groups. There were no significant differences in synovial fluid OC concentrations between groups. However, synovial fluid concentrations of 5D4 and HA were significantly decreased in OA and RA (see table 1). There were some significant $(p<0.05)$ associations between OC, HA, and 5D4 in the patients and controls. In serum the correlation coefficient $r$ between between OC and 5D4 was -0.55 in OA and 0.53 in RA. A positive correlation $(r=0.68)$ between concentrations of serum $O C$ and HA was also found in OA serum. In synovial fluid correlations were found in RA patients between concentrations of OC and HA $(r=0.69)$ and in OA patients between HA and 5D4 concentrations $(r=0.57)$.

\section{Discussion}

This study is one of a number of investigations undertaken to explore the relation between local synovial fluid OC and circulating serum OC in human joint disease..$^{3-5}$ Synovial fluid from healthy controls is not readily available for comparison, and to our knowledge, this is the first report that includes OC measurement of paired synovial fluid and serum from healthy controls. Comparisons were made between OC concentrations, proposed markers of cartilage aggrecan degradation, and synovial inflammation in different body fluid compartments in OA, RA, and healthy controls.

The concentrations of synovial fluid OC was significantly lower than serum concentrations in the patients and controls. Similar results were found in other studies ${ }^{3-5}$ suggesting that most of the synovial fluid OC is derived from the blood. In healthy controls and RA patients there was a clear relation between the concentration of $\mathrm{OC}$ in serum and synovial fluid. The correlation was weaker in patients with OA perhaps because of increased local bone turnover.
Serum OC is known to increase with age and is generally higher in women than men. ${ }^{1213}$ Moreover we have reported here that synovial fluid OC concentrations also increase with age but seem to be higher in men than women. Accordingly, patient's OC concentrations ought to be compared with age and sex matched healthy controls. In this study because of the difficulty of obtaining synovial fluid from normal controls, an age and sex matched range was not available for comparison. However we have used the ratio of synovial fluid/serum OC for comparison between groups, which is unlikely to be influenced by demographic difference (age and sex) and therefore may represent a more accurate measurement of changes in the subchondral bone.

RA patients showed significantly lower synovial fluid/serum OC ratios than OA patients and healthy controls, whereas the ratio values of OA patients were similar to the controls. Studies of serum OC concentrations in RA patients have shown discrepant findings with reports of increased, ${ }^{14}$ reduced, ${ }^{15}$ or normal ${ }^{16}$ concentrations of serum OC compared with healthy controls. These different results may reflect heterogeneity of bone involvement in RA, the influence of different variables on serum OC concentration, or methodological differences in the OC assay.

$\mathrm{HA}$ and 5D4 results contrasted with $\mathrm{OC}$ in that synovial fluid concentrations were very much higher than serum in all patients and controls (on average HA was 10000 times and 5D4, 20 times higher in synovial fluid compared with serum), suggesting local production of $\mathrm{HA}$ and $\mathrm{KS}$ in the joint, a finding that has been previously reported. ${ }^{917}$ No correlation between synovial fluid and serum concentrations of HA were found in patients with OA, RA or controls and the same was true for $5 \mathrm{D} 4$. This result is not surprising, as serum concentrations are probably influenced by the release of HA and 5D4 from many arthritic joints as well as metabolism in the whole skeleton, thus only a small fraction of serum HA and 5D4 is derived from the knee joint where the synovial fluid was aspirated. Finally, our finding that there are some associations between the putative markers of bone turnover, cartilage aggrecan degradation, and synovial inflammation in both OA and RA are rather intriguing and support the generally held views that the joint functions as an organ and in arthritis metabolic changes in the tissues of the joint are interrelated.

In conclusion, the results show that in all cases serum concentrations of OC were higher than synovial fluid concentrations indicating that most synovial fluid OC is derived from the circulating blood.

1 Thompson PW. Laboratory markers of joint inflammation and damage. Br J Rheumatol 1987;26:83-5

2 Cormier C. Markers of bone metabolism. Current Opin Rheumatol 1995;7:243-8.

3 Campion GV, Delmas PD, Dieppe PA. Serum and synovial fluid osteocalcin (Bone GLA protein) levels in joint disease. Br J Rheumatol 1989;28:393-8.

4 Saxne T, Zunino L, Heinegard D. Incresed release of bone sialoprotein into synovial fluid reflects tissue destruction in rheumatoid arthritis. Arthritis Rheum 1995;38:82-90. 
5 Mattie JP, Ferrera V, Boutsen Y, Franceschi JP, Botti D, de Boissezon C, et al. Serum and synovial fluid osteocalcin in rheumatic 12 .

6 Kellgren JH, Lawrence JS. Radiological assessment of osteoarthritis. Ann Rheum Dis 1957;16:494-502.

7 Arnett FC, Edworthy SM, Bloch DA, McShane DJ, Fries $\mathrm{JF}$, Cooper NS, et al. The American Rheumatism Association 1987 revised criteria for the classification of rheumatoid arthritis. Arthritis Rheum 1988;31:315-24

8 Sharif M, Osborne DJ, Meadows K, Woodhouse SM, Colvin EM, Shepstone L, et al. Chondroitin sulphate isomers and proteoglycan markers in synovial fluid from healthy volunteers and patients with arthritis. $\mathrm{Br}$ Rheumatol 1996;35:S239.

9 Thonar EJ-MA, Lenz ME, Klintworth GK, Caterson B, Pachman LM, Glickman P, et al. Quantification of keratan sulphate in blood as a marker of cartilage catabolism. sulphate in blood as a marker

10 Goldberg RL. Enzyme-linked immunosorbent assay for hyaluronate using cartilage proteoglycan and an antibody hyaluronate using cartilage proteoglycan and an antibod

11 Creamer P, Sharif M, George E, Cushnaghan J, Dieppe P. Intra-articular hyaluronic acid in osteoarthritis of the knee joint: an investigation into mechanisms of action. Osteoarthritis Cartilage 1994;2:133-40.
12 Epstein S, Poser J, McClintock R, Johnston jr CC, Bryce G, Hui S. Differences in serum bone Gla protein with age and sex. Lancet 1984;i:307-10.

13 Delmas PD, Stenner D, Wahner HW, Mann KG, Riggs BL. Increase in serum bone g-carboxyglutamic acid protein with aging in women: implications for the mechanism of age-related bone loss. J Clin Invest 1983;71:1316-21.

14 Gevers G, Devos P, De Roo M, Dequeker J. Increased levels of osteocalcin (serum bone Gla-protein) in rheumatoid arthritis. Br J Rheumatol 1986;25:260-2.

15 Ekenstam EAF, Ljunghall S, Hallgren R. Serum osteocalcin in rheumatoid arthritis and other inflammatory arthritides: relation between inflammatory activity and effect of glucocorticoid and remission including drugs. Ann Rheum Dis 1986;45:484-90.

16 Franck H, Ittel TH, Tasch O, Herborn G, Rau R. Osteocalcin in patients with rheumatoid arthritis - effect of anatomical stages, inflammatory activity and therapy. Rheumatol Int 1992;12:207-11.

17 Campion GV, McCrae F, Schnitzer TJ, Lenz ME, Dieppe PA, Thonar E-JMA. Levels of keratan sulphate in the serum and synovial fluid of patients with osteoarthritis of the knee. Arthritis Rheum 1991;34:1254-9.

\section{ARD \\ Annals of the Rheumatic Diseases}

will be present at the 61 st National American College of Rheumatology meeting in Washington D C, 8-12 November 1997.

Visit us at our stand \#346.

For further information and details about the authors and referees drinks reception, contact Prue Napthine on +44 (0) 115985 7112 or Ruth Straube on +44 (0) 171383 6486.

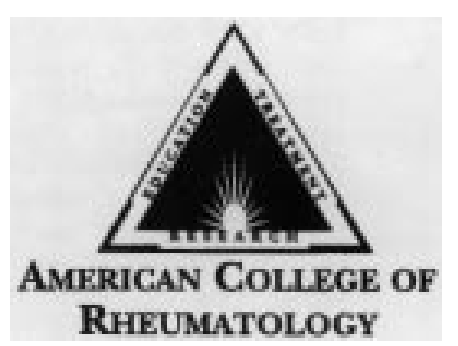

RHEUMATOLOGY 